University of Nebraska - Lincoln

DigitalCommons@University of Nebraska - Lincoln

Faculty Publications, Department of Psychology

Psychology, Department of

$5-14-2005$

\title{
Juror Reactions to Jury Duty: Perceptions of the System and Potential Stressors
}

\author{
Brian H. Bornstein \\ University of Nebraska-Lincoln, bbornstein2@unl.edu \\ Monica Miller \\ University of Nebraska-Lincoln, mkmiller@unr.edu \\ Robert J. Nemeth \\ University of Nebraska-Lincoln \\ Gregory L. Page \\ University of Pittsburgh at Bradford, glp5@upb.pitt.edu \\ Sarah Musil \\ University of Nebraska-Lincoln
}

Follow this and additional works at: https://digitalcommons.unl.edu/psychfacpub

Part of the Psychiatry and Psychology Commons

Bornstein, Brian H.; Miller, Monica; Nemeth, Robert J.; Page, Gregory L.; and Musil, Sarah, "Juror Reactions to Jury Duty: Perceptions of the System and Potential Stressors" (2005). Faculty Publications, Department of Psychology. 160.

https://digitalcommons.unl.edu/psychfacpub/160

This Article is brought to you for free and open access by the Psychology, Department of at DigitalCommons@University of Nebraska - Lincoln. It has been accepted for inclusion in Faculty Publications, Department of Psychology by an authorized administrator of DigitalCommons@University of Nebraska - Lincoln. 


\title{
Juror Reactions to Jury Duty: Perceptions of the System and Potential Stressors
}

\author{
Brian H. Bornstein, Ph.D., M.L.S., ${ }^{*}$ University of Nebraska-Lincoln \\ Monica K. Miller, J.D., Ph.D., University of Nebraska-Lincoln \\ Robert J. Nemeth, Ph.D., University of Nebraska-Lincoln \\ Gregory L. Page, Ph.D., M.L.S., University of Pittsburgh at Bradford \\ Sarah Musil, B.A., University of Nebraska-Lincoln
}

\begin{abstract}
Jurors were surveyed on their general perceptions of the court system and factors that may cause stress immediately after trial, after participating in a post-trial debriefing, and a month after trial. Jurors had an overall positive view of the court system but did report some perceived inequities. The two most stressful elements of jury duty were related to the complexity of the trial and the decision-making involved in the trial, although jurors reported low levels of stress overall. Women reported more stress than men, and trial characteristics such as trial length also affected stress levels. The debriefing intervention was perceived as helpful, but jurors' stress levels were similar at pre-and post-debriefing. Finally, although stress on some measures was lower at the 1 month follow-up, this reduction was not moderated by whether or not jurors received the debriefing.
\end{abstract}

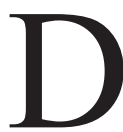

espite the popular notion of people dreading jury duty and doing virtually anything to get out of it, jurors surveyed after completion of jury duty typically have positive attitudes concerning their experiences (Diamond, 1993). For example, a recent study conducted by the National Center for State Courts (NCSC) found that the majority of jurors did not perceive jury duty as annoying or a waste of time, were proud of their accomplishments, would look back on jury duty with fondness, and would volunteer for jury duty in the future (NCSC, 1998). However, this view is not uniformly

*Correspondence to: Brian H. Bornstein, 335 Burnett Hall, Department of Psychology, University of Nebraska, Lincoln, NE 68588-0308, U.S.A. E-mail: bbornstein2@unl.edu

A large number of people helped make this research possible. We are especially grateful for the assistance of Danielle Bertrand, Judd Choate, Ramzi Dewing, Debra Hope, Darcy King, Brenda Lindsay, Jessica Miles, Elizabeth Neeley, Denise Robeson, Alan Tomkins, Sara Zabawa, the Nebraska Minority \& Justice Task Force, and the judges and bailiffs of the Lancaster County District and County Courts.

Contract/grant sponsor: University of Nebraska-Lincoln Tobacco Settlement Biomedical Research Enhancement Fund. 
positive. Members of the venire who were not selected did not have as positive feelings as those who actually served on a jury (NCSC, 1998).

Surveys of the general public also provide mixed results. For example, respondents in another NCSC study had a fairly positive view of the legal system: They believed that courts protect the rights of defendants, that litigants have adequate representation, and that judges are honest and fair (NCSC, 1999). On the other hand, there were concerns that courts are too costly and slow and do not give equal attention to all cases (NCSC, 1999; Rottman, Hansen, Mott, \& Grimes, 2003).

An area of particular concern is the courts' treatment of minorities. Past research suggests that minorities themselves (Brooks \& Jeon-Slaughter, 2001; Rottman \& Tomkins, 1999), as well as the public at large (NCSC, 1999; Rottman et al., 2003), perceive inequities based on race. The 1999 NCSC report was based on the results of 1,826 telephone interviews with a sample that represented the ethnic mix of the country. The participants generally agreed that juries do not adequately represent the community, and that people who are wealthy, Caucasian, or English speaking receive better treatment than people who lack these characteristics. For example, participants were asked "What kind of treatment do various groups receive from the courts?" and were given the options "Far better treatment," "Somewhat better treatment," "Same treatment," "Somewhat worse treatment," and "Far worse treatment." Eighty percent of participants believed that wealthy people received "far better" or "better" treatment, and 55\% of the participants felt that non-English speaking people received "somewhat worse" or "far worse" treatment in the courts.

\section{JUROR STRESS}

Despite jurors' generally favorable attitudes toward jury service, serving as a juror might be difficult or stressful for a variety of reasons. The NCSC (1998) asked 401 jurors or alternate jurors from a wide range of civil and criminal cases (e.g. robbery, drunk driving, malpractice, and personal injury) to rate the level of perceived stress they experienced from a list of stressors. The top ten sources of stress for jurors from non-death-penalty cases were: (1) Deciding on a verdict, (2) jury deliberations and discussions, (3) disruptions to daily routine, (4) fear of making a mistake, (5) violent crimes, (6) jury selection (i.e. voir dire/jury panel), (7) crime against children, (8) answering questions in front of other people, (9) sentencing a criminal defendant and (10) dissension/differences among jurors.

Thus, at the most mundane level, jurors might be stressed by being presented with an unfamiliar task and by having to disrupt their daily routine (e.g. missing work, changing childcare arrangements). According to the NCSC(1998) manual for dealing with juror stress, these "routine" stressors also include perceived lack of control, inefficient use of time, unresponsive court staff, and an unpleasant environment.

Jurors may also experience stress knowing that trials entail real consequences for the litigants. In criminal cases, consequences of a conviction can include prison, fines, or even death; while in civil cases, there can be monetary penalties and damage to one's reputation. An awareness of the consequences flowing from a jury's verdict contributes to the "burden of justice"; that is, jurors' sense of responsibility for their decisions, and a realization that what they are doing matters (Haney, Sontag, \& Costanzo, 1994). 
Case characteristics can be another source of discomfort for jurors. Trial testimony can be disturbing, technical, or dull; judge's instructions can be complex and confusing (Diamond, 1993; Greene \& Bornstein, 2000; Mott, Hans, \& Simpson, 2000); and the deliberation process can be contentious. Jurors who find themselves in a minority position during deliberation, or even afterwards in cases where unanimity is not required, are especially likely to experience stress. For example, the NCSC (1998) found that $33 \%$ of jurors surveyed experienced some level of stress due to "being in a minority position during jury deliberations," and 56\% of jurors experienced some level of stress as a result of "dissension/differences among jurors." Finally, in rare, highly sensationalized cases, there can be intense media scrutiny and/or sequestration, as in recent high-profile trials such as of those of O. J. Simpson, John Allen Muhammad, Martha Stewart, and Tyco executives (see, generally, Murphy, Loveland, \& Munsterman, 1992). In the recent Tyco case, for example, media pressure, which included public disclosure of one juror's name, was a large factor in the declaration of a mistrial (Lin, 2004; Sorkin \& Glater, 2004).

Several studies have documented significant stress reactions among jurors. For example, some jurors show elevated symptoms of anxiety, sleeplessness, headaches, hives, high blood pressure, and alcohol consumption (Kaplan \& Winget, 1992; Kelley, 1994; NCSC, 1998). Although these symptoms would rarely qualify jurors for a formal psychiatric diagnosis such as post-traumatic stress disorder or depression (Feldmann \& Bell, 1993; Shuman, Hamilton, \& Daley, 1994), they occur at significant sub-clinical levels, are most prevalent in long or high-stakes (e.g. death penalty) trials (Costanzo \& Costanzo, 1994; NCSC, 1998), and can last for several months after trial (Bell \& Feldmann, 1992; Shuman et al., 1994).

Nearly all prior studies of juror stress have focused on jurors' experiences in difficult murder trials or serious felony cases (Feldman \& Bell, 1993; Hafemeister, 1993; Kelley, 1994). These cases typically receive substantial publicity, contain extremely disturbing evidence (e.g. gruesome photographic evidence of murder victims or emotionally charged testimony), and may require sequestration. Graphic evidence can elicit a negative emotional response in jurors, which might then prejudice jurors' judgments (Bornstein \& Nemeth, 1999; Fishfader, Howell, Katz, \& Teresi, 1996). In a notable exception to the focus on such extreme cases, the NCSC (1998) study of juror stress indicated that jurors in less severe cases might also experience mild stress reactions, due to anxiety, irritation, or boredom.

\section{ATTEMPTS TO MITIGATE STRESS}

Most attempts to mitigate juror stress take one of two forms: pre-trial efforts to educate prospective jurors about what their task entails, and post-trial interventions, such as debriefings led by mental health professionals. Pre-trial interventions are typically educational in nature and are intended to prevent or reduce the impact of stress (Bienen, 1993). These proactive interventions provide general information about juror stress, teach jurors to identify stress symptoms, and provide jurors with coping techniques (Bienen, 1993; Dabs, 1992).

In cases where the judge suspects that jurors have experienced significant stress, judge- or clinician-led debriefings can be provided. These sessions primarily allow jurors 
an opportunity to vent and share experiences (Hafemeister, 1993; Hafemeister \& Ventis, 1992; NCSC, 2000). For example, Feldman and Bell (1991, 1993) were asked to provide post-trial debriefing sessions in several highly publicized cases containing gruesome evidence, such as the Jeffrey Dahmer murder trial and others involving victim dismemberment or disfigurement. These debriefing studies suggest that jurors do experience strong emotional responses and an overwhelming sense of responsibility, and that talking about it afterwards can be beneficial.

\section{LIMITATIONS OF PRIOR RESEARCH}

These prior attempts to investigate juror stress are informative and encouraging, but they are nonetheless limited. First, in focusing on the most extreme cases (e.g. those involving the death penalty or gruesome evidence) the majority of studies overlook possible stressors in the more routine aspects of jury duty. Second, there has been little effort to address the influence of demographic variables. Although one study (Kaplan \& Winget, 1992) found that symptoms of stress were reported more frequently by women than men, little is known about the effects of stress on different populations.

Third, the findings of previous studies have been largely anecdotal and based on a small sample of jurors. For example, Feldman and Bell $(1991,1993)$ indicated that jurors appeared to appreciate the debriefing process because it allowed them an opportunity to express their frustrations and stress. However, the jurors were not asked whether the process was helpful, and their stress levels were not assessed. They studied a very small number of highly sensationalized cases, and the debriefing sessions variously included the jurors, the judge, the jailer, the court reporter, and the bailiff. While the findings of these case studies are informative, the results may not generalize to other kinds of trial.

Fourth, the few studies that have looked at the effectiveness of juror debriefing (e.g. Bell \& Feldmann, 1992; Feldmann \& Bell, 1991, 1993; Holt, Slick, \& Rayborn, 2003; NCSC, 2000) provide a promising foundation, but they are limited from a scientific perspective. For example, the debriefings used were relatively unstructured (e.g., some have been conducted by a mental health professional, whereas others have been conducted by a judge; and none has used a structured script), so it is impossible to know why the debriefing worked, or whether it worked at all. Furthermore, previous studies have not included a control, non-debriefed condition for purposes of comparison. A control condition is essential to assess the effectiveness of any sort of treatment variable, as any improvement from pre-debriefing to post-debriefing could merely reflect the passage of time or some other variable.

Finally, previous studies have not systematically addressed the time course of longterm stress effects. Although some studies have conducted follow-up sessions months after the end of trial, these studies did not systematically compare jurors who had received debriefings with those who had not (Bell \& Feldmann, 1992; Feldmann \& Bell, 1991, 1993; Holt et al., 2003). For example, Holt and colleagues (2003) conducted follow-up surveys with jurors up to a year after the trial in order to assess their perceptions of stress 
and the post-verdict debriefing. Because this follow-up surveyed only jurors who had received a debriefing, it is unclear whether the jurors who received debriefings experienced less stress months after the trial than those who did not receive debriefings.

The present study sought to address these shortcomings in several ways. First, this study included a sample of jurors from a variety of cases: relatively severe criminal trials (e.g. manslaughter, child abuse) as well as more routine cases (e.g. narcotics possession, civil contract disputes). The debriefing was structured and delivered according to a treatment manual developed by mental health professionals.

Moreover, a host of measurements were used to assess levels of stress, depression, and anxiety. In addition, demographic data were collected to allow for comparisons based on characteristics such as jurors' sex. Jurors completed these stress measurements immediately after the trial to measure initial stress levels. Some jurors then participated in a posttrial debriefing and completed the measures again. Finally, approximately one month after the trial, both jurors who did receive the debriefing and jurors who did not receive the debriefing were surveyed again. This design allowed for the assessment of debriefing's effectiveness at reducing stress symptoms, by comparing participants who did or did not receive a debriefing. These methods helped to reduce or eliminate some of the limitations of past studies, thereby furthering the existing body of knowledge concerning juror stress and juror perceptions.

\section{RESEARCH QUESTIONS}

This study involved five major research questions. Some of these questions were associated with specific hypotheses, while others were more exploratory in nature.

\section{Research Question 1: How Do Jurors Perceive the Court System?}

Based on previous juror surveys, we expected that jurors would have an overall positive impression of the court system (NCSC, 1998). For example, we expected that most jurors would indicate that jury duty was not a waste of time and would be proud of their accomplishments (NCSC, 1998). However, we also expected that jurors would perceive some inequities in the court system, such as minorities and low-income individuals having a more difficult time accessing the court system (NCSC, 1999).

\section{Research Question 2: Is Involvement in the Justice System a Source of Stress for Ju- rors? If So, What are the Major Causes of Stress?}

To address this question, we assessed possible stress caused by a variety of general (e.g. missing work, voir dire) and trial-specific (e.g. civil versus criminal, trial length, presence of complex or upsetting evidence) factors. 


\section{Research Question 3: What is the Time Course of Stress?}

Jurors were surveyed immediately after trial and again approximately one month later. Because the vast majority of psychological symptoms diminish over time (Lambert \& Bergin, 1994), we predicted that any stress in jurors would as well.

\section{Research Question 4: Does Stress Vary as a Function of Jurors' Demographic Characteristics?}

Based on previous research (Kaplan \& Winget, 1992), we predicted that overall stress would be greater for females than males. The inclusion of a large variety of potential stressors allowed us to assess whether male and female jurors were affected differentially by various stress factors.

\section{Research Question 5: Does Post-Trial Intervention, or "Debriefing," Mitigate the Negative Effects of Jury Duty?}

Based on previous research (Feldmann \& Bell, 1991, 1993), we predicted that the posttrial debriefing would mitigate stress reactions. We also assessed whether any benefit varied for men versus women, or as a function of trial characteristics (e.g. civil versus criminal).

\section{METHOD}

\section{Trial Selection and Participants}

\section{Trial Selection}

Trials were selected for inclusion in consultation with bailiffs for state and county courts in a single mid-sized county (population approximately 250,000) in a Midwestern state. An attempt was made to sample an array of case types and to balance civil/criminal trials. Thus, the trial selection procedure was non-random, but in selecting trials for inclusion, the researchers knew nothing about a case except the presiding judge, the type of case, and starting date (i.e., we knew nothing about the identity of the litigants or nature of the evidence). The majority of trials were held in state court and had 12 jurors, but four trials (held in county court) had only 6 jurors. County court trials involved lesser criminal charges or civil cases involving smaller potential damages.

Data were obtained from 28 total trials: 19 civil and 9 criminal (see Table 1). Most civil trials were tort cases, although three claims were for breach of contract. Eleven of the tort cases concerned a claim of vehicular negligence; two of these cases dealt solely with the issue of damages. All nine criminal trials involved different offenses. 
Table 1. Trials included in the study (number of cases)

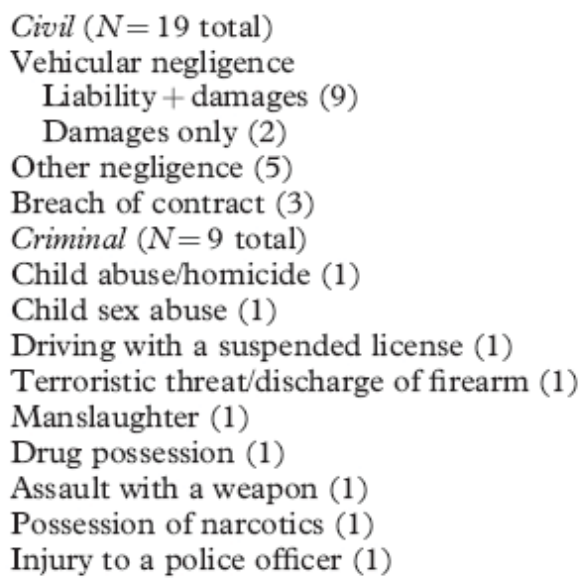

The "other" negligence cases included professional negligence (e.g. legal or medical malpractice), a slip-and-fall case, etc.

\section{Participants}

One hundred and fifty-nine jurors participated in the study, out of approximately 310 who were asked to participate. The sample was $56 \%$ female and predominantly Caucasian (151 Caucasian, 2 African-American, 1 Hispanic, 1 Asian-American, 1 Native American, 1 Arab-American, 1 “other," and 8 unspecified). ${ }^{1}$ Participants' ages ranged from 20 to 80, with a mean of 43.2 years. Fifty-seven percent were Protestant, 19\% were Catholic, 6\% were Agnostic or Atheist, and 24\% were "other" or an unspecified religion. Thirty-six percent were Democrats, $42 \%$ were Republicans, $22 \%$ were Independent or not registered, and $6 \%$ did not specify their political affiliation.

\section{Materials and Procedure}

Data collection consisted of three phases. Phase 1 involved administration of a post-trial survey; Phase 2 involved a debriefing session (for some participants) and post-debriefing survey; Phase 3 involved a one-month follow-up survey.

\section{Phase 1}

After delivering a verdict, jurors were asked to participate in a post-trial survey, which contained the following components.

- Perceptions of their jury experience and the justice system in general (37 items; see the appendix). Jurors rated their agreement/disagreement (on a 4 point scale) with questions such as "Your jury reflected the racial and ethnic mix of the com-

\footnotetext{
${ }^{1}$ The figures for race and sex do not differ greatly from the composition of the state $(91 \%$ Caucasian and $51 \%$ female; 2000 U.S. Census).
} 
munity," "I am proud of what I accomplished during jury duty," "The defendant in your case received a fair trial," and "In [your state], Whites have greater access to information about the courts and their rights." Most questions were drawn or modified from previous research (e.g. NCSC, 1999). A few questions asked for descriptive information (e.g. "How many jurors were on your jury?") or required jurors to select a response from a set of alternatives (e.g. "On the whole, how seriously did the jury take its job? - Not at all seriously, somewhat seriously, very seriously").

- $\quad$ Ratings of possible stress factors (32 items; see the appendix). Twenty-five items assessed a variety of potential stressors identified in previous research (e.g. Kaplan \& Winget, 1992; Kelley, 1994; Shuman et al., 1994), including evidence variables (photographs or videos of victims or crime scene, verbal testimony, etc.), process variables (long days in court, length of trial, disruption to routine, etc.), juror interactions (e.g. being in a minority position and disagreements among jurors), and decision consequences (knowledge of what the verdict could mean, fear of making a mistake, etc.). These items were rated on a 5 point Likert scale ranging from "not at all upsetting/stressful" to "extremely upsetting/stressful". Seven items, drawn from a Posttraumatic Stress Disorder diagnostic scale (Foa, Cashman, Jaycox, \& Perry, 1997), assessed the extent to which stress affected participants' functioning (e.g. Feeling emotionally numb, Feeling irritable or angry, Having trouble concentrating). Participants were asked to rate on a 5 point Likert scale how much the PTSD items described their experience as a juror.

- Mood assessment. There were two additional measures of mood/affect: the Center for Epidemiological Studies Depression Scale (CESDS; 20 items; Fischer \& Corcoran, 1994) and the State component of the State-Trait Anxiety Inventory (STAI; 20 items; Spielberger, Gorsuch, \& Lushene, 1970). The CESDS includes 10 positively worded and 10 negatively worded items that are rated on a 4 point Likert scale. The positively worded items were reverse scored and composites were calculated by summing the scores. The possible scores on the CESDS range from 0 to 60 . The STAI also uses a 4 point rating scale; scores can therefore range from 20 to 80 . Missing data points for specific questions were replaced with the participant's mean score calculated for the entire instrument.

- Demographics. Finally, participants provided demographic information (19 items, e.g. sex, occupation, income level, etc.).

Jurors were paid $\$ 20$ to complete the post-trial survey, which took approximately 45 minutes. A number of jurors in the first several trials declined to participate due to time constraints. From the sixth trial onward, jurors were therefore offered the choice of completing the survey in person and immediately after trial, or taking a packet home with them, to be mailed back to the researchers within one week of the trial. Thirty-four jurors completed the survey in person, and 124 jurors completed the survey and mailed it back to the researchers. In-person and mail-back participants did not differ in their CESDS post-trial or post-debriefing scores, their STAI post-trial or post-debriefing scores ( $t$ s $<0.97, p s>0.34)$, age $(t(156)=0.70, p=0.48)$, sex, race, or religion $(p s>0.51)$. The groups did differ in political affiliation $\left(\chi^{2}(2)=11.67, p<0.05\right)$. In-person participants were more likely to be independent/not registered $(42 \%)$ or Democrats $(36 \%)$ than Re- 
publicans (21\%). On the other hand, mail-back participants were more likely to be Republicans $(47 \%)$ than either Democrats $(36 \%)$ or Independent/not registered (17\%). Because in-person and mail-back participants did not differ in significant ways (other than political affiliation), the two groups were combined for the remainder of the analyses.

\section{Phase 2}

The second phase consisted of the "debriefing" session. The session was identical for inperson and mail-back participants, although the timing varied: The former participated immediately after Phase 1, and the latter were scheduled to participate after receipt of their Phase 1 materials. Thus, the debriefing occurred later for the mail-back participants, but nearly all were within one week after receipt of the Phase 1 materials. ${ }^{2}$ There were 49 participants (22 male, 27 female) included in the debriefing component of this study. The majority of the participants were involved in civil trials $(n=31)$ compared with criminal trials ( $n=16$; information about the type of trial for two participants was not available).

The 45 minute debriefing session, for which participants received an additional \$20, was conducted by one of two Ph.D.-level psychologists. In order to standardize the debriefing sessions, a treatment manual based on the cognitive-behavioral approach proposed by Donald Meichenbaum (Meichenbaum \& Genest, 1980) was developed specifically for this study. The debriefing sessions involved a short introduction to the session, which included an explanation of the purpose of the session and a discussion of the limits of confidentiality. Additionally, the debriefing sessions included a general debriefing component that allowed the jurors to discuss their overall experiences as jurors. Following the general debriefing component, two psycho-educational components were introduced: The first addressed general physiological and psychological aspects of stress, while the second introduced basic coping strategies. The possible long-term effects of stress were also introduced. Throughout the educational components, the participants were asked to identify aspects of their experiences as jurors that had been stressful.

At the conclusion of the session, participants completed a survey identical to the Phase 1 survey, with the addition of three questions (rated on a 5 point Likert scale) designed to assess the debriefing's effectiveness: (1) "How helpful was it to talk about your jury experience?;" (2) "How helpful was it to learn about skills to manage stress?;" (3) "Overall, how helpful was the session you just had with the discussion leader?" Finally, the participants received a handout that outlined the coping strategies discussed as well as a list of possible referrals for mental health providers in the community.

\section{Phase 3}

All participants who completed Phase 1 were asked to participate in a follow-up telephone survey. Thus, the follow-up survey included both participants who attended the de-

\footnotetext{
${ }^{2}$ To avoid a selection bias, initially participants were asked if they would be willing to participate in Phase 2 , and half of those who were willing were randomly selected to participate. Because this procedure yielded relatively few participants in Phase 2, it was eventually dispensed with, and all participants who were willing to participate in the debriefing did so. Although this raises the possibility that those who participated in the debriefing were, by self-selection, those most likely to benefit from it, we felt that the opportunity to gather more data, given the exploratory nature of the study, outweighed this risk. In addition, the relatively small impact of the debriefing session (see below) suggests that any such bias was minimal.
} 
briefing and participants who did not complete the debriefing phase. Ninety participants agreed to participate, a response rate of $56.7 \%$. If participants had indicated that they were willing to do the follow-up phase, we made three attempts to contact them, with the first attempt occurring four weeks after trial. Participants completed this phase of the study between four and seven weeks after trial.

The follow-up questionnaire, which took approximately 10-15 minutes to complete, included a subset of the Phase 1 measures (e.g. perceptions of jury duty, ratings of how stressful various factors were, CESDS, STAI), as well as one additional question: "How would you respond the next time you are called for jury duty?" The response options were (a) ignore it; (b) try and get out, lying if necessary; (c) try and get out, but truthfully; (d) try to be selected, lying if necessary; (e) try to be selected, but truthfully; or (f) try neither to be selected nor to get out of it. Participants received $\$ 10$ for their participation in this phase of the study.

\section{RESULTS}

\section{Trial Summary Data}

Of the 17 civil cases where liability was contested, six reached a verdict for the defendant, six reached a verdict for the plaintiff, three verdicts (involving comparative negligence) were split, and four verdicts were unknown. ${ }^{3}$ When the verdict was for the plaintiff, the mean damage award was \$49,243 (range \$2,850-\$259,578.63). Six criminal defendants were found guilty, two were found not guilty, and one was guilty of one offense but not guilty of another. Trials lasted from one to six days. On average, civil trials had fewer witnesses $(M=4$, range $1-8)$ than criminal trials $(M=9$, range 2-18). Deliberations ranged from 30 minutes to 1.5 days $(M=2.76 \mathrm{~h}$ civil, $2.85 \mathrm{~h}$ criminal).

\section{Phase 1: Post-Trial Survey}

\section{General Perceptions of Jury Duty}

Overall, jurors had a positive view of their jury service. Nearly all jurors felt that the jury selection process was fair (98\%), and that the defendant received a fair trial $(99 \%)$. The various legal actors were perceived favorably as well: 100\% felt that the judge, attorneys, and court personnel were respectful and courteous, and $98 \%$ believed that they communicated effectively. However, only 57\% reported that, compared to how they felt before involvement in this trial, they now felt better or much better about how our justice system works; and 55\% agreed that, in order to encourage participation, jurors should be paid more for their services.

\footnotetext{
${ }^{3}$ Researchers were not allowed to remain in the courtroom during deliberations. Thus, we had to rely on the bailiffs to notify us when the verdict was about to be announced. In a few cases, we were not notified in time to hear the verdict.
} 


\section{Perceptions of Minority Treatment}

There were positive and negative aspects to jurors' perceptions of minority treatment. On the one hand, jurors did not feel that minorities were selectively eliminated during jury selection; of the 57 jurors who indicated that a minority had been eliminated from their jury panel, only one juror $(0.6 \%)$ felt that race had been a factor in the elimination. Further, only a minority of jurors agreed that Whites have better access to information about courts and their rights (28\%), English speakers receive better treatment (20\%), or minorities cannot get fair treatment (9\%). On the other hand, although $83 \%$ felt that juries should reflect the ethnic diversity of the community, only $36 \%$ felt that their jury did reflect that diversity. Similarly, only $38 \%$ felt that court personnel reflected diversity. Also of concern, $59 \%$ agreed that immigrants may be less likely to use the court system, $49 \%$ agreed that minority litigants have difficulty affording representation, and $76 \%$ agreed that income affects the quality of legal representation.

\section{Potential Stressors}

Two of the 25 items, "being sequestered" and "deciding on the death penalty," were dropped because they did not occur in any of the sampled trials. The remaining 23 potential stressors were subjected to a principal component factor analysis with Varimax rotation. Seven factors were extracted with eigenvalues greater than 1.0 (total variance explained $=64.33 \%$ ). Table 2 contains the items comprising each factor and the factor loadings. With one exception (Factor 7), all factors had moderate to high reliability ( $\alpha$ levels ranged from 0.58 to 0.81 ). The mean for each factor, which is an average of all the items comprising that factor, provides an indication of the relative stress level (on a 1-5 scale) assigned to that factor.

The means for all factors ranged from 1.18 to 2.02 (on a 5 point scale), suggesting that overall jurors in the present sample of trials did not experience a great deal of stress. The greatest amount of variance, $13.59 \%$, was explained by a "Disruption to daily life" factor $(\alpha=0.81, M=1.85, S D=0.72)$, consisting of five items (e.g. long days in court, length of trial; see Table 2). "Trial complexity" (three items, e.g. difficulty understanding the law or testimony; $\alpha=0.66, M=1.92, S D=0.73$ ) explained the next largest amount of variance, $10.48 \%$.

The remaining factors, in descending order of variance explained, were "Evidence reactions" (four items, e.g. feelings for the victim/plaintiff or defendant; 9.78\% variance explained, $\alpha=0.77, M=1.55, S D=0.60$ ); "Decision making" (four items, e.g. knowledge of what the verdict could mean, having limited input; $9.17 \%$ variance explained, $\alpha=0.71$, $M=2.02, S D=0.68$ ); "Jury duty" (three items, e.g. waiting for assignment to trial; $8.76 \%$ variance explained, $\alpha=0.71, M=1.75, S D=0.68$ ); "Juror interactions" (two items, e.g. being in a minority position; $6.55 \%$ variance explained, $\alpha=0.58, M=1.64, S D=0.84$ ); and "External sources" (2 items, e.g. fear of reprisal; 6.01\% variance explained, $\alpha=0.33$, $M=1.18, S D=0.45)$.

These seven factors were each subjected to a 2 (type of trial: civil versus criminal) $\times 2$ (length of trial: long versus short, as determined by a median split) $\times 2$ (juror sex) ANO- 
Table 2. Principal component analysis of potential stressors

\begin{tabular}{|c|c|c|c|c|c|c|c|}
\hline \multirow[b]{2}{*}{ Item } & \multicolumn{7}{|c|}{ Factor loadings } \\
\hline & $\begin{array}{l}\text { Disruption } \\
\text { to routine c }\end{array}$ & $\begin{array}{c}\text { Trial } \\
\text { complexity }\end{array}$ & $\begin{array}{l}\text { Evidence } \\
\text { y reactions }\end{array}$ & $\begin{array}{l}\text { Decision } \\
\text { making }\end{array}$ & $\begin{array}{l}\text { Jury } \\
\text { duty }\end{array}$ & $\begin{array}{l}\text { Juror } \\
\text { interaction }\end{array}$ & $\begin{array}{l}\text { External } \\
\text { sources }\end{array}$ \\
\hline Eigenvalue & 3.13 & 2.41 & 2.25 & 2.11 & 2.01 & 1.51 & 1.38 \\
\hline Long days in court & 0.837 & & & & & & \\
\hline Length of trial & 0.831 & & & & & & \\
\hline Disruption to normal routine & 0.707 & & & & & & \\
\hline Length of deliberations & 0.658 & & & & & & \\
\hline Trial interruptions & 0.586 & & & & & & \\
\hline Difficulty understanding law & & 0.793 & & & & & \\
\hline Difficulty deciding guilt & & 0.779 & & & & & \\
\hline $\begin{array}{l}\text { Difficulty understanding } \\
\text { testimony }\end{array}$ & & 0.485 & & & & & \\
\hline Photos or videos & & & 0.751 & & & & \\
\hline Verbal testimony & & & 0.734 & & & & \\
\hline Feelings for victim/plaintiff & & & 0.630 & & & & \\
\hline Feelings for defendant & & & 0.570 & & & & \\
\hline Not being able to discuss & & & & 0.719 & & & \\
\hline $\begin{array}{l}\text { Knowledge of what verdict } \\
\text { could mean }\end{array}$ & & & & 0.587 & & & \\
\hline Fear of making a mistake & & & & 0.531 & & & \\
\hline Having limited input & & & & 0.510 & & & \\
\hline Reporting for jury duty & & & & & 0.828 & & \\
\hline Waiting for assignment to trial & & & & & 0.814 & & \\
\hline Jury selection process & & & & & 0.453 & & \\
\hline Being in a minority position & & & & & & 0.740 & \\
\hline Disagreements among jurors & & & & & & 0.548 & \\
\hline Fear of reprisal & & & & & & & 0.800 \\
\hline Publicity & & & & & & & 0.527 \\
\hline
\end{tabular}

Two variables were not included in the factor structure: "being sequestered" and "deciding on the death penalty," as neither of these variables was applicable to the sampled cases.

VA. There was only one effect of type of trial: Jurors in criminal trials reported more stress from the "External sources" factor than jurors in civil trials $(p<0.05)$. Jurors in longer trials reported significantly more stress associated with the "Disruption to daily life" $(p<0.01)$ and "Trial complexity" factors $(p<0.05)$ than jurors in shorter trials.

As predicted, women jurors reported significantly more stress associated with several factors: "Jury duty" $(p<0.001)$, "Juror interactions" $(p<0.05)$, and "External sources" ( $p$ $<0.001)$. Women were also marginally more affected by "Evidence reactions" $(p<0.07)$. There were no interactions, except for an uninterpretable three-way interaction on the Juror interactions factor.

In addition to the ratings of potential stressors, we assessed stress reactions by asking jurors whether they or other jurors experienced stress, and by having them rate seven PTSD items. More than one-third (38.5\%) of jurors agreed that they had experienced stress as a result of their jury duty. This figure is consistent with the NCSC study (1998), in which a similar percentage $(33 \%)$ of jurors reported experiencing stress. Surprisingly, however, $57.8 \%$ of jurors agreed that other jurors had experienced stress as a result of their jury duty. Thus, there was a tendency for jurors to perceive stress where none in fact might have existed, or to under-report their own stress levels. 
With the exception of sex differences, there were few effects on the PTSD measures. Jurors in criminal trials reported being significantly more jumpy or easily startled than jurors in civil trials $(p<0.05)$. Women reported having more upsetting thoughts $(p<$ $0.01)$, feeling more distant or cut off $(p<0.01)$, and feeling more emotionally numb $(p<$ $0.05)$ than men.

\section{Depression and Anxiety}

There were no effects on post-trial CESDS or STAI levels of trial type, sex, or trial length, all $F \mathrm{~s}<2.0$.

\section{Phase 2: Debriefing}

Paired $t$-tests were calculated to assess whether significant differences existed between post-trial (i.e. pre-debriefing) and post-debriefing reports of anxiety or depression. For the STAI, the mean pre-and post-debriefing scores were $46.57(S D=4.84)$ and 46.65 $(S D=4.29)$, respectively, $t=0.11, p>0.05$. The mean pre-and post-debriefing depression scores on the CESDS were $7.08(\mathrm{SD}=6.99)$ and $6.66(S D=7.80)$, respectively, $t=$ $0.48, p>0.05$.

Although there were no overall significant differences found between pre-debriefing and post-debriefing levels of anxiety and depression, the participants reported a subjective impression that the debriefing sessions were beneficial, with $73.5 \%$ of the participants reporting that talking about their experience was moderately, very, or extremely helpful. Additionally, $75.5 \%$ of the participants reported that it was moderately to extremely helpful to learn about how to cope with stress in general. Furthermore, 83.7\% of the participants reported that overall the session was moderately to extremely helpful. Hence, as in other studies that have found a positive perception of debriefing sessions (Feldmann \& Bell, 1991, 1993), the majority of jurors found these sessions to be beneficial.

\section{Phase 3: Follow-Up}

Phase 1 scores on the STAI, CESDS, PTSD, and stress factors were compared with scores on the same measures during Phase 3, in order to determine whether there were significant changes in scores over time. Sex, trial length, trial type, and participation in debriefing were included as between-subjects independent variables in these repeated-measures analyses to determine whether these variables moderated any reduction in stress, depression, or anxiety.

\section{STAI and CESDS}

There was a reduction in both anxious (STAI: Ms $=28.6$ versus 27.4) and depressive symptomatology (CESDS: $M \mathrm{~s}=6.75$ versus 5.4 ), though neither was statistically significant $(F \mathrm{~s}<2.53, p \mathrm{~s}>0.05)$. 
The repeated-measures analyses indicated that debriefed participants did not experience greater stress reduction in terms of either the STAI $(F(1,61)=0.94, p>0.05)$ or $\operatorname{CESDS}(F(1,57)=0.003, p>0.05)$ measure (i.e., there was no significant interaction between debriefing participation and the time of measurement variable). Additionally, the effect of time was the same for men and women $\left(F_{\mathrm{S}}<2.2\right)$, for both long and short trials $\left(F_{\mathrm{S}}<0.9\right)$, and for civil and criminal trials $\left(F_{\mathrm{S}}<2.8\right)$.

\section{Stress Factors}

There was no significant reduction in stress level on any of the seven stress factors $(F \mathrm{~S}$ $<2.3, p s>0.05)$, except for a marginal effect on the External sources factor $(F(1,61)$ $=3.11, p=0.08)$. On this factor, follow-up scores were lower $(M=1.1)$ than scores immediately post-trial $(M=1.23)$, indicating that stress levels due to external sources (publicity, fear of reprisal) decreased somewhat over time. The effect of time on the seven stress factors was not moderated by participation in a debriefing, length of trial, or trial type.

While there was no main effect of time on stress from Juror interactions $(F(1,61)=$ $2.84, p>0.05)$, there was an interaction with $\operatorname{sex}(F(1,61)=5.69, p<0.05)$. Women decreased in stress due to this factor from post-trial $(M=1.71)$ to follow-up $(M=1.58)$, whereas men increased in stress $(M=1.34$ to $M=1.63)$. There was a similar marginally significant interaction on the Jury duty factor $(F(1,61)=3.47, p=0.068)$, showing that women tended to decrease in stress over time $(M \mathrm{~s}=1.92$ to 1.81$)$, while men tended to increase in stress over time $(M \mathrm{~s}=1.38$ to 1.53$)$.

On the PTSD items, there were no significant changes from post-trial to follow-up on any of the measures $(F \mathrm{~s}<2.4)$. Further, the effect of time on these variables was not moderated by sex, length of trial, trial type, or whether the participant received a debriefing $\left(F_{\mathrm{S}}<2.7\right)$.

\section{Perceptions of Jury Duty and Debriefing}

There was no change on any of the eight items assessing perceptions of jury duty from immediately post-trial to follow-up. Thus, jurors' opinions about their service became neither more nor less favorable as they had time to reflect. A new question added to the follow-up survey asked participants how they would respond the next time they were called for jury duty. Nearly half $(49.4 \%)$ said they would "neither try to be selected nor to get out of it," $43.8 \%$ said they would "try to be selected, but truthfully," and $5.6 \%$ said they would "try to get out of jury duty, but truthfully." Only one participant $(1.1 \%)$ said he or she would "try and get out, lying if necessary," and no participants said they would lie in order to be selected or would simply ignore the summons. The responses to other questions supported this strong endorsement of jury duty: $92 \%$ were proud of what they accomplished during jury duty, $89 \%$ would volunteer for jury duty in the future, $96 \%$ felt that jury duty was not a waste of time, and $89 \%$ felt that the jury took its job seriously.

Participants who had attended a debriefing session evaluated that session by answering the same questions that they had answered immediately after the debriefing. Although the 
Table 3. Perceived helpfulness of debriefing session

\begin{tabular}{lcc}
\hline & Mean at debriefing & Mean at follow-up \\
\hline Helpful to talk* & 3.03 & 2.48 \\
Helpful to learn about stress coping skills* & 3.07 & 2.23 \\
Was the session overall helpful?* & 3.13 & 2.60 \\
\hline
\end{tabular}

$* p<0.05$.

debriefing was perceived positively at the time it took place, the passage of time significantly decreased this perception (see Table 3 for means). Specifically, after a month had passed, jurors found it less helpful to have talked about their jury experience $(t(30)=2.80$, $p<0.01)$ or to have learned about stress coping skills $(t(29)=4.63, p<0.001)$. The session was also rated as less helpful overall $(t(29)=3.76, p<0.001)$.

\section{DISCUSSION}

We frame our discussion of the data according to each of the questions raised in the Introduction.

\section{Research Question 1: How do Jurors Perceive the Court System?}

Perceptions of jury duty on the whole were generally positive. Nearly all jurors felt that both they and the litigants had been treated fairly. Perhaps most strikingly, over $40 \%$ of jurors said that the next time they were summoned, they would actually try to be selected; this figure was approximately seven times greater than the proportion who said they would try to get out of jury duty the next time.

Perceptions of minority treatment and involvement were positive in some respects but negative in others. Positive findings, for example, were that only $9 \%$ of respondents agreed that minorities cannot get fair treatment in the court system, and only $20 \%$ felt that English speakers receive better treatment. However, negative results included the findings that $59 \%$ felt that immigrants may be less likely to use the court system, and $76 \%$ agreed that income affects the quality of legal representation. If these perceptions mirror reality, then the findings provide a clear indication that courts could do more to provide equal access to all people.

\section{Research Question 2: Is Involvement in the Justice System a Source of Stress for Ju- rors? If So, What are the Major Causes of Stress?}

Overall, jurors in the present sample experienced relatively low levels of stress. Nonetheless, nearly $40 \%$ reported experiencing at least some stress, which is consistent with previous research (e.g. NCSC, 1998); and some aspects of the experience proved more stressful than others. The greatest amounts of stress resulted from elements of the decisionmaking task itself (e.g. knowing what the verdict could mean for the parties involvedwhat we referred to earlier as the "burden of justice"), trial complexity (e.g. comprehen- 
sion difficulties), and disruption to jurors' daily routine. Consistent with previous research (Kaplan \& Winget, 1992; Kelley, 1994; NCSC, 1998; Shuman et al., 1994), clinical measures of stress (i.e. the depression and anxiety scales) showed that jurors' stress levels fell short of clinical significance.

The relatively crude classification of type of trial (civil versus criminal) had minimal effect on any of the stress measures. The high degree of variability within the broad categories of civil and criminal trials (e.g. severity, duration, complexity) likely washed out any real differences between them. Supporting this interpretation, length of trial-regardless of trial type - significantly affected stress levels, especially stress associated with relevant procedural factors (i.e. Disruption to daily life and trial complexity). These effects add validity to the factor structure, as it stands to reason that trials' disruptiveness and complexity will both increase monotonically with trial duration.

\section{Research Question 3: What is the Time Course of Stress?}

The passage of time resulted in somewhat lower levels of anxiety and depression, although these reductions did not reach statistical significance. There was a marginally significant reduction over time in stress due to External sources. Debriefed participants did not show greater stress reduction than participants who were not debriefed. Similarly, length and type of trial did not moderate stress reduction. On the Jury duty and Juror interactions factors, females reported a reduction in stress over time, whereas males actually reported an increase on these stress factors at follow-up. The relatively stable time course of stress is certainly due at least in part to the low level of initial stress. Nonetheless, stress due to some factors did diminish over time, at least for female jurors, suggesting that stress effects might dissipate naturally; and the curious pattern showing an increase in some types of stress among male jurors warrants further study.

\section{Research Question 4: Does Stress Vary as a Function of Jurors' Demographic Characteristics?}

Consistent with previous research (e.g. Kaplan \& Winget, 1992), women jurors reported significantly more stress than men on several factors. Specifically, women jurors reported more stress associated with their interactions with fellow jurors, general jury duty variables such as being selected as a juror, and external stressors such as fear of reprisal, than did men jurors. The literature suggests that women in general are more likely to admit experiencing stress than men (American Psychiatric Association, 2000), and this appears to hold true in the jury context as well. Of course, it is hard to disentangle the extent to which female jurors actually experienced more stress, as opposed to merely reporting more stress (American Psychiatric Association, 2000); but the increase over time in some types of stress among males suggests that it is not just a reporting bias. 


\section{Research Question 5: Does Post-Trial Intervention, or "Debriefing," Mitigate the Negative Effects of Jury Duty?}

There was little support for changes in the level of stress or depression as a result of the psycho-educational debriefing sessions. This is at least partly due to the fact that the overall levels of stress were fairly low to begin with, making any further reduction difficult. Moreover, although stress levels decreased to some extent over time, this decrease was not greater for debriefed than for non-debriefed participants. Nonetheless, participants overwhelmingly perceived the debriefing as helpful, especially immediately after it took place. There is doubtless some value to these "feel good" effects of debriefing, which are consistent with previous studies (Feldmann \& Bell, 1991, 1993). Future studies should continue to examine the effects of debriefing interventions in a systematic fashion, to determine whether debriefings have genuine objective benefits and not merely subjective benefits.

Even the subjective benefits of the debriefing must be qualified by the fact that the perception of helpfulness decreased over time. Participants' memory of the debriefing's benefits could simply have faded, or the post-debriefing scores could have been elevated by demand characteristics. Specifically, the questions were first asked in the post-debriefing survey, which was conducted by the debriefer him/herself. This could have artificially inflated scores if participants had a desire to please the debriefer by indicating that the debriefing was helpful. On the other hand, the follow-up questions were asked by a different researcher, and over the phone instead of with the debriefer present; thus the participants might not have felt this need to please. Previous debriefing studies have not assessed the debriefing's effectiveness after the passage of time. Because the present results suggest that a debriefing's afterglow wears off, those interested in facilitating jury performance should be cautious about recommending debriefing to the exclusion of other strategies, such as pre-trial interventions (Dabs, 1992).

\section{Limitations and Future Directions}

One limitation of this study is that the sample of jurors did not allow for comparisons between Caucasian and minority jurors. It is possible that Caucasian jurors may have different perceptions of the court system, especially with respect to the treatment of minorities, and different reactions to stress factors than minority jurors. We find it nonetheless significant that even among the predominantly Caucasian sample, jurors perceived some demographic groups (e.g. immigrants, the poor) as receiving disparate treatment.

It is also possible that the jurors who agreed to participate are not representative of the class of jurors as a whole; that is, jurors who declined to participate might have experienced more or less stress than that reported by the present sample. Unless judges in similar studies require jurors to participate (an unlikely and arguably unethical possibility), this limitation cannot be ultimately resolved. Nonetheless, evidence that the present data are reasonably representative comes from two sources. First, over 50\% of jurors (159 of approximately 310) agreed to participate, which is a fairly high response rate. Second, there was little difference between participants who participated in the different formats 
(i.e. in person versus mail-back), suggesting - though not proving - that jurors who did and did not participate would not differ much either.

There are several possible explanations for why little benefit from debriefing was found in the present study. First, it is possible there may have been a priming effect for the instruments. The majority of the items in the pre-and post-debriefing surveys were identical, a fact commented upon by some of the participants during the second administration of the survey. Furthermore, the measures used (CESDS and STAI) may not have been sensitive to changes occurring over such a short period of time. Future studies could administer different stress measures to try to overcome this limitation.

It is also possible that the jurors simply did not find the trials to be that distressing. Overall, the levels of stress and depression reported before the debriefing sessions were relatively low. If the individual was not experiencing much distress initially, then a debriefing session would not be expected to reduce levels of stress to a significant degree. Although this is inconsistent with previous research that reported high levels of juror stress (e.g. Feldmann \& Bell, 1991, 1993), those studies have tended to emphasize particularly gruesome cases. The present finding of low stress among jurors is encouraging, as the vast majority of trials are likely to involve fairly routine, unsensational disputes.

Future analysis could involve coding trials for severity of the charge against the defendant or the extent of the plaintiff's injury. It is likely that stress levels would be higher in more extreme cases (e.g., manslaughter) than in more mundane cases (e.g. contract disputes), at least for stress due to trial-specific factors such as explicit testimony; however, stress from more mundane factors, such as disruption to jurors' routine, should be fairly constant across trial types. The present findings demonstrate that the longer that routine is disrupted, the greater the stress.

Because the present study did not control for pre-existing stress in the participants, we cannot definitively conclude that any post-trial stress was due to trial participation. It would be desirable to collect baseline measures of stress prior to trial; unfortunately, the judges who participated in the present study would not allow this, out of concerns about biasing or oversensitizing jurors prior to their service. Although we cannot therefore exclude the possibility that reported stress levels were partially influenced by pre-existing factors, the finding that nearly $40 \%$ of jurors reported at least some stress immediately after trial suggests that much of it was due to their trial participation. Moreover, this figure is sufficiently high to be cause for concern, whatever its source.

It is also important to replicate the present findings in an alternate jurisdiction. Such replication could confirm the sources-of-stress factor structure identified here using a different constellation of trials, a different sample of jurors, and a different set of court procedures. Finally, levels of distress, particularly in high-stress trials, should be monitored for longer than the one-month period employed here, in order to assess how levels of distress modulate naturally over time.

\section{Summary and Conclusions}

This study was designed to investigate several questions about the experiences of jury duty: Is jury duty a positive experience? Are there perceived inequities in the court system? What factors cause stress? Can a post-trial debriefing alleviate stress? 
In sum, jurors overall expressed positive views of the court system and relatively low levels of stress, though female jurors experienced greater stress than male jurors. Jurors perceived a debriefing as helpful, but it failed to reduce stress on any of the objective measures, suggesting that post-trial interventions may not be necessary or beneficial in run-of-the-mill cases. Nonetheless, the findings of the present study support the need for further evaluation of stress and the benefits of debriefing sessions in the court system. As Diamond (1993) notes, it is important to understand jurors' reactions for a number of reasons. For example, jurors who have negative experiences are likely to try to avoid service in the future and will share their negative experiences with others.

Perhaps most importantly, understanding the possible sources of juror dissatisfaction or concern provides opportunities to enhance the performance of future juries (Diamond, 1993). Future studies of jurors' reactions should examine both mundane cases and those that are likely to include relatively high levels of stressful or emotional evidence and testimony (e.g. child abuse, homicide). Only a handful of studies have attempted to measure juror stress, and the present study adds to that growing database. These studies provide a foundation upon which to build a better understanding of jurors' experience.

\section{APPENDIX}

Perceptions of Jury Experience and Justice System

1. How many jurors were on your jury?
16 jurors
29 jurors
312 jurors
4 Other

2. Of those who served on your jury (including yourself), how many were ethnic or racial minorities?

3. Before the trial began, the attorneys and/or judge questioned potential jurors (voir dire). In your opinion, was this process fair?

1 Yes

2 No

3 Not Sure (please elaborate)

4. During voir dire, were any ethnic or racial minorities eliminated as potential jurors?

1 One or more minorities were questioned and eliminated.

2 One or more minorities were eliminated without being questioned.

3 One or more minorities were questioned, but not eliminated.

4 No minorities were questioned or eliminated.

5 There were no minorities among the potential jurors. 
5. If a racial or ethnic minority was eliminated as a potential juror, in your opinion was that person not selected due to his or her race or ethnicity?

1 Yes

2 No

3 There were no minorities who were eliminated.

6. Was an interpreter used at any point during the trial?

1 Yes

2 No

7. Did you take off work for jury duty?

1 Yes

2 No

8. If you answered "yes" to Question \#7, is your employer paying your normal salary while you serve?

1 Yes

2 No

9. How long did your trial last? Please measure from the time the attorneys and judges started the jury selection process, to when the jury delivered its verdict. days hours (if the whole trial lasted less than 1 full day)

10. How long did you wait before jury selection started for the trial on which you ended up serving as a juror?

days

hours (if you waited less than 1 full day)

11. Were you the jury foreperson on this jury?

YES

$\mathrm{NO}$

12. How many times have you previously served on a jury, and on what kind of trial? criminal trials; and civil trials.

13. Was your jury sequestered (i.e., isolated) during the course of the trial?

YES $\mathrm{NO}$

14. The defendant in your case received a fair trial.

1 Strongly agree

2 Agree

3 Disagree

4 Strongly disagree

15. The judge, attorneys, and court personnel communicated effectively with the defendant.

1 Strongly agree

2 Agree

3 Disagree

4 Strongly disagree

16. The judge, attorneys, and court personnel were respectful and courteous to the defendant.

1 Strongly agree 
2 Agree

3 Disagree

4 Strongly disagree

17. Your jury reflected the racial and ethnic mix of the community.

1 Strongly agree

2 Agree

3 Disagree

4 Strongly disagree

18. The judge, attorneys and court personnel reflected the racial and ethnic mix of the community.
1 Strongly agree
2 Agree
3 Disagree
4 Strongly disagree

19. I am proud of what I accomplished during jury duty.

1 Strongly agree

2 Agree

3 Disagree

4 Strongly disagree

20. I would volunteer for jury duty in the future.

1 Strongly agree

2 Agree

3 Disagree

4 Strongly disagree

21. Jury duty was a waste of my time.

1 Strongly agree

2 Agree

3 Disagree

4 Strongly disagree

22. I experienced stress as a result of my jury duty.

1 Strongly agree

2 Agree

3 Disagree

4 Strongly disagree

23. I think other jurors experienced stress during jury duty.

1 Strongly agree

2 Agree

3 Disagree

4 Strongly disagree

24. Did the judge have a private discussion with the jury after the verdict? YES $\mathrm{NO}$

25. If you answered "No" to Question 24, how would a chance to discuss your experience with the judge have made you feel about your experience as a juror? 
much worse somewhat worse the same somewhat better much better $\begin{array}{lllll}1 & 2 & 3 & 4 & 5\end{array}$

26. Compared to other members of your jury, how much did you participate during deliberations?

much worse somewhat worse the same somewhat better much better

$\begin{array}{lllll}1 & 2 & 3 & 4 & 5\end{array}$

27. On the whole, how seriously did the jury take its job?

not at all seriously somewhat seriously very seriously

123

28. Compared to how you felt before your involvement in this trial, how do you feel now about how our justice system works?

1 much better

2 somewhat better

3 the same

4 somewhat worse

5 much worse

29. Compared to how you felt before your involvement in this trial, how is your overall mood right now?

1 much better

2 somewhat better

3 the same

4 somewhat worse

5 much worse

30. In Nebraska, personal income affects quality of legal representation.

1 Strongly agree

2 Agree

3 Disagree

4 Strongly disagree

31. In Nebraska, whites have greater access to information about the courts and their rights.
1 Strongly agree
2 Agree
3 Disagree
4 Strongly disagree

32. New immigrants to the state are not as likely to make use of the court system as those who have lived in Nebraska for a long time.

1 Strongly agree

2 Agree

3 Disagree

4 Strongly disagree

33. English speakers receive better treatment by judges, attorneys and court personnel, than non-English speakers.

1 Strongly agree 
2 Agree

3 Disagree

4 Strongly disagree

34. In Nebraska, minority litigants have more difficulty than white litigants affording quality legal representation from a lawyer.

1 Strongly agree

2 Agree

3 Disagree

4 Strongly disagree

35. Minority representation on juries should reflect the diversity of the community.

1 Strongly agree

2 Agree

3 Disagree

4 Strongly disagree

36. In order to encourage participation jurors should be paid more for their services.

1 Strongly agree

2 Agree

3 Disagree

4 Strongly disagree

37. In Nebraska, minorities cannot get fair treatment in the legal system.

1 Strongly agree

2 Agree

3 Disagree

4 Strongly disagree

\section{Possible Stress Factors}

For questions 38-62, use a 1-5 scale, where:

$1=$ not all upsetting/stressful

2 = slightly upsetting/stressful

3 = moderately upsetting/stressful

$4=$ very upsetting/stressful

$5=$ extremely upsetting/stressful

You may use any number between 1 and 5. If a particular question does not apply to your trial, please leave it blank or enter "N/A."

On a scale from 1 (not at all) to 5 (extremely), how upsetting or stressful was:

38. Reporting for jury duty.

39. Waiting for assignment to a trial.

40. Difficulty understanding complex testimony.

41. Difficulty understanding and applying the law (i.e., judge's instructions).

42. Difficulty deciding whether the defendant was guilty or not guilty (liable or not liable, for a civil trial). 
43. Photographs or videos presented as evidence (e.g., pictures of victims, crime scene, etc.)

44. Verbal testimony presented as evidence (e.g., descriptions of injuries).

45. Your feelings for the victim (or plaintiff) and the victim's family.

46. Your feelings for the defendant and the defendant's family.

47. Fear of making a mistake and reaching the wrong verdict.

48. The jury selection (voir dire) process.

49. The overall length of the trial, excluding deliberations.

50. The length of the deliberations.

51. Long days in the courtroom and/or overall length of the trial.

52. Trial interruptions and/or delays.

53. Disruption to your normal daily routine.

54. Publicity and media coverage about the trial.

55. Disagreements among jurors during deliberation; relationshipswith other jurors.

56. Your being in a minority position during deliberations.

57. Not being able to discuss the case with others outside the jury, or with other jurors until deliberation.

58. The knowledge of what a guilty (or liable) verdict could mean for the defendant (i.e., the size/type of criminal sentence or civil damage award).

59. Deciding whether or not to give the death penalty (if applicable).

60. Having limited input during trial; not being allowed to ask questions.

61. Being sequestered during the trial (if applicable).

62. Fear of reprisal or concerns for your own personal safety.

For questions 63-69, answer to what extent each statement describes a problem that bothered you with respect to your experience since being selected as a juror in this trial. Your answers should include your experience in the courtroom and jury room, as well as in your daily life while the trial was going on (e.g., during court recess or when court was not in session during a multi-day trial).

Please use the following scale:

$1=$ not at all

$2=$ lightly

$3=$ moderately

$4=$ very much

$5=$ extremely 
On a scale from 1 (not at all) to 5 (extremely), how descriptive of your experience was each of the following?

63. Having upsetting thoughts or images about the trial that came into your head when you didn't want them to.

64. Feeling distant or cut off from people around you.

65. Feeling emotionally numb (for example, being unable to cry or unable to have loving feelings).

66. Feeling irritable or having fits or anger.

67. Having trouble concentrating (for example, drifting in and out of conversation).

68. Being overly alert (for example, checking to see who is around you, being uncomfortable with your back to a door, etc.)

69. Being jumpy or easily

\section{REFERENCES}

American Psychiatric Association. (2000). Diagnostic and statistical manual (IV-TR). Washington, DC: Author.

Bell, R. A., \& Feldmann, T. B. (1992). Crisis debriefing of juries: A follow-up. American Journal of Preventive Psychiatry, 4, 2-6.

Bienen, L. B. (1993). Helping jurors out: Post-verdict debriefing for jurors in emotionally disturbing trials. Indiana Law Journal, 68, 1333-1355.

Bornstein, B. H., \& Nemeth, R. J. (1999). Jurors' perception of violence: A framework for inquiry. Aggression and Violent Behavior, 4, 77-92.

Brooks, R. R. W., \& Jeon-Slaughter, H. (2001). Race, income and perceptions of the U.S. court system. Behavioral Sciences and the Law, 19, 249-264.

Costanzo, M., \& Costanzo, S. (1994). The death penalty: Public opinions, legal decisions, and juror perspectives. In M. Costanzo, \& S. Oskamp (Eds.), Violence and the law (pp. 246-272). Thousand Oaks, CA: Sage.

Dabs, M. O. (1992). Jury traumatization in high profile criminal trials: A case for crisis debriefing? Law and Psychology Review, 16, 201-216.

Diamond, S. S. (1993). What jurors think: Expectations and reactions of citizens who serve as jurors. In R. E. Litan (Ed.), Verdict: Assessing the civil jury system (pp. 282-305). Washington, DC: Brookings Institution.

Feldmann, T. B., \& Bell, R. A. (1991). Crisis debriefing of a jury after a murder trial. Hospital and Community Psychiatry, 42, 79-81.

Feldmann, T. B., \& Bell, R. A. (1993). Juror stress: Identification and intervention. Bulletin of the American Academy of Psychiatry and the Law, 21, 409-417.

Fischer, J., \& Corcoran, K. (1994). Measures for clinical practice: A sourcebook, Volume 2: Adults (2nd ed.). New York: Free Press.

Fishfader, V. L., Howells, G. N., Katz, R. C., \& Teresi, P. S. (1996). Evidential and extralegal factors in juror decisions: Presentation mode, retention, and level of emotionality. Law and Human Behavior, 20, 565-572.

Foa, E. B., Cashman, L., Jaycox, L., \& Perry, K. (1997). The validitation of a self-report measure of posttraumatic stress disorder: The Posttraumatic Diagnostic Scale. Psychological Assessment, 9 , 445-451. 
Greene, E., \& Bornstein, B. H. (2000). Precious little guidance: Jury instruction on damage awards. Psychology, Public Policy, and Law, 6, 743-768.

Hafemeister, T. L. (1993). Juror stress. Violence and Victims, 8, 177-186.

Hafemeister, T. L., \& Ventis, W. L. (1992). Juror stress: What burden have we placed on our juries? State Court Journal, 16, 35-46.

Haney, C., Sontag, L., \& Constanzo, S. (1994). Deciding to take a life: Capital juries, sentencing instructions, and the jurisprudence of death. Journal of Social Issues, 50, 149-176.

Holt, R., Slick, J., \& Rayborn, A. (2003, July). Understanding jurors: Jury debriefing in Yamhill County. Oregon State Bar Bulletin, 63, 17-25. Retrieved October 24, 2003, from Westlaw.

Kaplan, S. M., \& Winget, C. (1992). The occupational hazards of jury duty. Bulletin of the American Academy of Psychiatry and the Law, 20, 325-333.

Kelley, J. E. (1994). Addressing juror stress: A trial judge's perspective. Drake Law Review, 43, $97-$ 125.

Lambert, M. J., \& Bergin, A. E. (1994). The effectiveness of psychotherapy. In Handbook of psychotherapy and behavior change (4th ed., pp. 143-189). New York: Wiley.

Lin, A. (2004, April 5). Lawyers voice concern over Tyco trial fallout. New York Law Journal. Retrieved April 5, 2004, from http://www.law.com/

Meichenbaum, D., \& Genest, M. (1980). Cognitive behavioral modification: An integration of cognitive and behavioral methods. In F. H. Kanfer, \& A. P. Goldstein (Eds.), Helping people change: A textbook of methods (2nd ed., pp. 390-422). New York: Pergamon.

Mott, N. L., Hans, V. P., \& Simpson, L. (2000). What's half a lung worth? Civil jurors' accounts of their award decision making. Law and Human Behavior, 24, 401-419.

Murphy, T. R., Loveland, G. K., \& Munsterman, G. T. (1992). Managing notorious cases. Williamsburg, VA: National Center for State Courts.

National Center for State Courts (NCSC). (1998). Through the eyes of the juror: A manual for addressing juror stress. Williamsburg, VA: National Center for State Courts.

National Center for State Courts (NCSC). (1999). How the public views the state courts: A 1999 national survey. Williamsburg, VA: National Center for State Courts.

National Center for State Courts (NCSC). (2000). King County Superior Court: Evaluation of the jury debriefing program: Final report. Williamsburg, VA: National Center for State Courts.

Rottman, D. B., Hansen, R., Mott, N., \& Grimes, L. (2003). Perceptions of the courts in your community: The influence of experience, race and ethnicity. Williamsburg, VA: National Center for State Courts.

Rottman, D., \& Tomkins, A. (1999). Public trust and confidence in the courts: What public opinion surveys mean to judges. Court Management Review, 36, 24-31.

Shuman, D. W., Hamilton, J. A., \& Daley, C. E. (1994). The health effects of jury service. Law and Psychology Review, 18, 267-307.

Sorkin, A. R., \& Glater, J. D. (2004, April 5). Jurors, fresh from deliberations, recall what led to Tyco mistrial. New York Times. Retrieved April 7, 2004, from http://www.nytimes.com/

Spielberger, C. D., Gorsuch, R. L., \& Lushene, R. E. (1970). Manual for the State-Trait Anxiety Inventory (self-evaluation questionnaire). Palo Alto, CA: Consulting Psychologists Press. 